\title{
APPLICATION OF ACTIVATED CARBON IN WASTE WATER TREATMENT
}

\author{
Anand Patel \\ Student \\ Department of CHE \\ Parul Insitute of \\ Technology, Parul \\ University, Vadodara, \\ Gujarat, India
}

\author{
Dolly Sharma \\ Student \\ Department of CHE \\ Parul Insitute of \\ Technology, Parul \\ University, Vadodara, \\ Gujarat, India
}

\author{
Pushpak Kharkar \\ Student \\ Department of CHE \\ Parul Insitute of \\ Technology, Parul \\ University, Vadodara, \\ Gujarat, India
}

\author{
Dr. Dhiraj Mehta \\ Assistant Professor \\ Department of CHE \\ Parul Insitute of \\ Technology, Parul \\ University, Vadodara, \\ Gujarat, India
}

\begin{abstract}
The effective usage of granular and powdered activated carbon made from agricultural waste into treatment of waste water. The industrial waste contains many chemicals, toxic waste like zinc, cobalt, nickel, iron, mercury, etc., industrial solid waste, etc. that causes great damage to human life and environment. The current problems in water and wastewater treatment is because of the increasing pollution of waters by organic compounds that are difficult to decompose biologically. The organic substances resist the selfpurification capabilities of the rivers as well as decomposition in conventional wastewater treatment plants. The cost effective activated carbon was prepared from the agriculture waste i.e. green coconut shell and was used in dye removal by varying concentration. The prepared activated carbon was characterized by FTIR (Fourier Transform Infrared Spectroscopy), SEM (Scanning Electron Microscopy) and XRD (X-Ray Diffraction).
\end{abstract}

Keywords - Activated Carbon, Green Coconut Shell, Muffle Furnace, Adsorption, XRD, FTIR, SEM

\section{INTRODUCTION}

Rapid industrialization has led to great increase in disposal of heavy metals into the environment. Over the past few decades there is tremendous increase in the use of the heavy metals resulting in an increased flux of metallic substances in the aquatic environment [1]. The impact of waste water is very harmful on human health as well as on environment, disease such as typhoid, dysentery, diarrhoea etc. As environmental pollution is the major problem nowadays so need of activated carbon is growing day by day. Its texture characteristics and surface properties depend on the raw material and on the method used for its preparation [2]. According to survey of 2018 by WHO potable drinking water available on earth is only about $4-4.8 \%$ and turbidity observed is 0.05 $\mathrm{mg} / \mathrm{lit}$ for harmful chemicals found in waste water of industries effluents. The $\mathrm{pH}$ limit for effluent of industries should be neutral but recently observed $\mathrm{pH}$ is 6-6.3. [3]. There are three main ways to treat the waste water 1]. Primary 2]. secondary 3]. Tertiary and adsorption of impurities from waste water by use of activated charcoal is primary of treatment.

The main objective of this study is the treatment of industrial effluent by the adsorption and using activated carbon as an adsorbent. This includes two major steps: (1) The preparation of activated carbon from agriculture waste and (2) Application of prepared absorbent in waste water treatment [5]. Adsorption has appeared as one of the promising methods for sequestration of harmful chemicals due to its low energy consumption, costeffectiveness, relatively simple technological process, non-corrosive to the equipment and it is applicable over a relatively wide range of temperatures and pressures [2]. Various different methods are available for colour and chemicals removal from waters and wastewaters such as membrane separation, aerobic and anaerobic degradation using various microorganisms, chemical oxidation, coagulation and flocculation, and reverse osmosis [3]. Zeolites and activated carbon are used widely as adsorbent due to its porous structure. Because large surface area provides more adsorption and high porosity leads to more diffusion [1].

The most important attributes of an adsorbent for any application are: adsorptive capacity, selectivity, regenerability, kinetics, compatibility and cost [5]. All the carbonaceous materials can be converted into activated carbon but coconut shells give high grade absorbent due to high carbon content, low ash content and mechanical strength. Activation is most important feature in waste water treatment. The activation can be carried out in rotary kilns fired directly or indirectly, multiple hearth furnace, fluidized bed reactor, static bed reactor (muffle furnace) or vertical retorts [6-8]. The contact time, initial dye concentration, mass dosage, temperature and $\mathrm{pH}$ effects the adsorption rate [3].

\section{MATERIALS AND METHODS}

Preparation of activated carbon

For the production of activated carbon from agriculture waste for the waste water treatment the most common raw material that can be used is green coconut shell. This is because of its easy availability i.e. approximately 243.8 million tonnes per year all over the world, 119 million 


\section{International Journal of Engineering Applied Sciences and Technology, 2019 Vol. 3, Issue 12, ISSN No. 2455-2143, Pages 63-66 \\ Published Online April 2019 in IJEAST (http://www.ijeast.com)}

tonnes per year in India, high carbon content, low ash content and good mechanical strength, so gives the high grade adsorbent. Moreover, the activated carbon manufactured from coconut shell has high porosity and is cost efficient.

The green coconut shells were collected and then cut into small pieces, followed by washing with water in order to remove the dust particles adhered to the surface, then the material was dried in sunlight for about 15 days. Later the dried material was kept inside the oven for $24 \mathrm{hr}$ at $150^{\circ} \mathrm{C}$ to remove the moisture content. After drying the material was crushed in a jaw crusher and sieved to size of approximately $400 \mu \mathrm{m}$. Chemical activation was done by using $\mathrm{H}_{2} \mathrm{SO}_{4}$. The precursor was carbonized at $500^{\circ} \mathrm{C}$ for $2 \mathrm{hr}$ in the absence of air in muffle furnace. Then the carbonized material was cooled and soaked with certain weight of $\mathrm{H}_{2} \mathrm{SO}_{4}$. This slurry was then kept into a muffle furnace for $4 \mathrm{hr}$ at $600^{\circ} \mathrm{C}$. The prepared sample was then washed several times by distilled water followed by heating in oven at $110^{\circ} \mathrm{C}$. The sample was weighed and sent for characterization and batch studies were carried out.

\section{RESULTS AND DISCUSSION}

\section{A. Sample Testing}

The adsorption experiment was carried out in batch process by using aqueous solution of methlylene blue of known concentration. The solutions of five different concentrations were prepared i.e. $0.0001 \mathrm{M}, 0.001 \mathrm{M}$, $0.002 \mathrm{M}, 0.01 \mathrm{M}, 0.02 \mathrm{M}$. These solutions were prepared by diluting methylene blue in distilled water. The calorimeter was set at $450 \mathrm{~nm}$ wavelength. The calibration curve was plotted for methylene blue concentration $\mathrm{v} / \mathrm{s}$ adsorbance (As shown in Fig 1). 200ml of stock solution was measured into required number of conical flasks in preparation for a batch adsorption equilibrium test. $1.25 \mathrm{~g}$ of the manufactured activated carbons was introduced into each batch solution. These solutions were mechanically agitated and the resultant decolourisation of the solutions was observed. Later, the solutions were filtered using filter paper and the filterate concentration was measured using calorimeter.

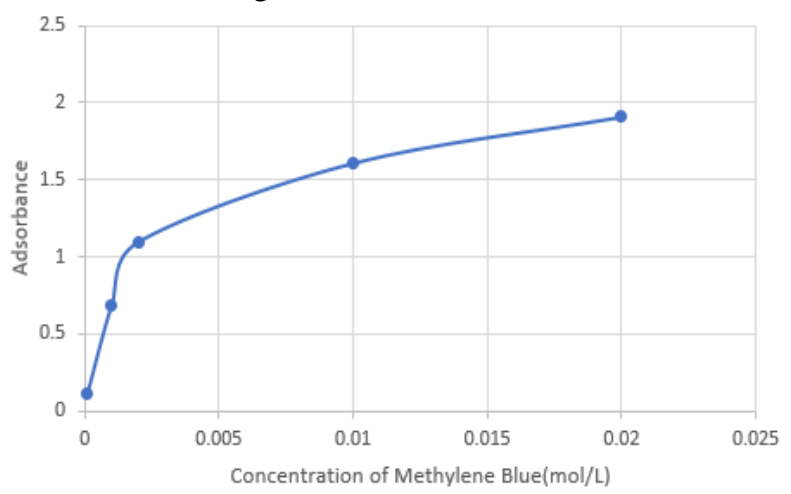

Fig 1. Calibration Curve

B. Characterization of prepared Activated Carbon Fourier Transform Infrared Spectroscopy analysis
FTIR is a method to identify the surface chemistry of a material. It can be used to identify the functional groups present in the sample. The FTIR analysis method uses infrared light to scan the test samples and observe its chemical properties. The sample is exposed to different wavelengths and the instrument measures which wavelength is absorbed. In most cases FTIR is used for detecting organic molecules and sometimes inorganic as well. It identifies the chemical bond present in a molecule. The main elements that must be present in activated carbon are oxygen, carbon, silicon and potassium.

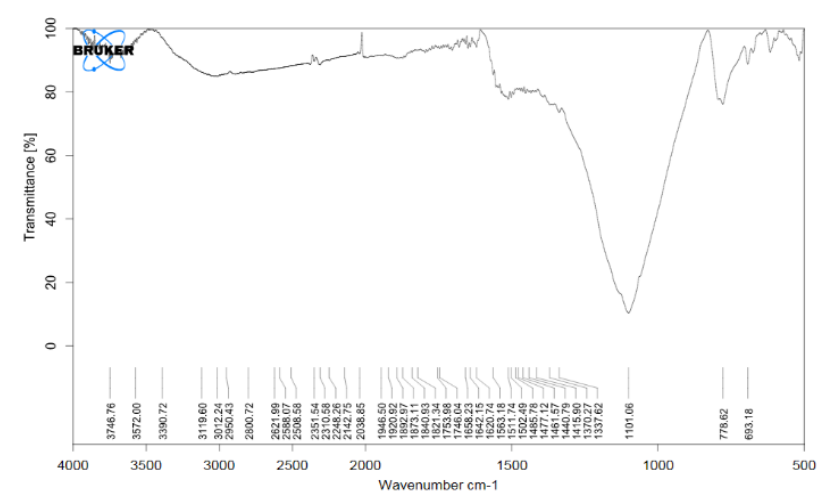

Fig 2. FTIR Analysis

A band at $1100 \mathrm{~cm}^{-1}$ is attributed to the C-O stretching vibration in hydroxyl and phenol groups. The frequency range $1470-1450 \mathrm{~cm}^{-1}$ shows the presence of the alkanes i.e. $\mathrm{C}-\mathrm{H}$ bond. A band at $1400 \mathrm{~cm}^{-1}$ shows the presence of N-H bond. Combination of bands at 1750 and 1100 $\mathrm{cm}^{-1}$ suggests the presence of predominantly carboxylic groups. (As shown in Fig 2)

\section{Scanning Electron Microscopy studies}

SEM uses a focused electron beam to generate various signals that can be used to obtain information about the surface topography and composition giving us complex and high magnification images.

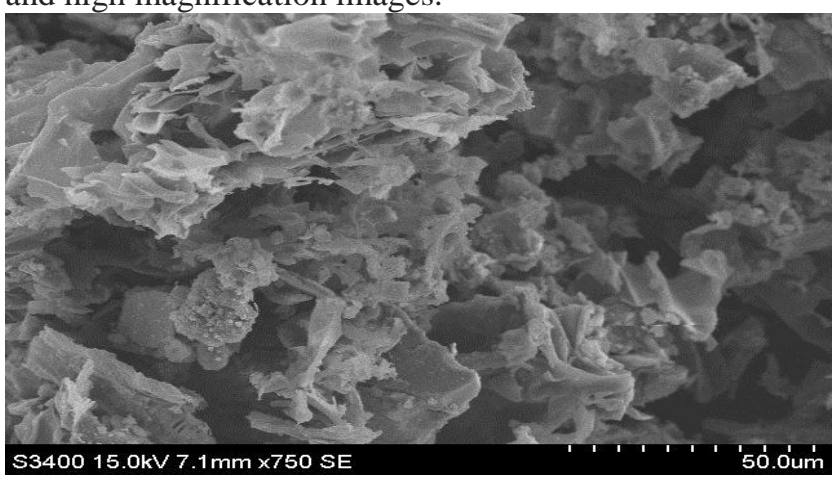

Fig 3. SEM photograph at 3400x magnification and 50 $\mu \mathrm{m}$ pore size

It is evident that the carbon particles are in the form of spherical particles of a wide range of sizes and the larger particles seem to be made up of aggregates of the smaller ones. (As shown in Fig 3 and Fig 4) 


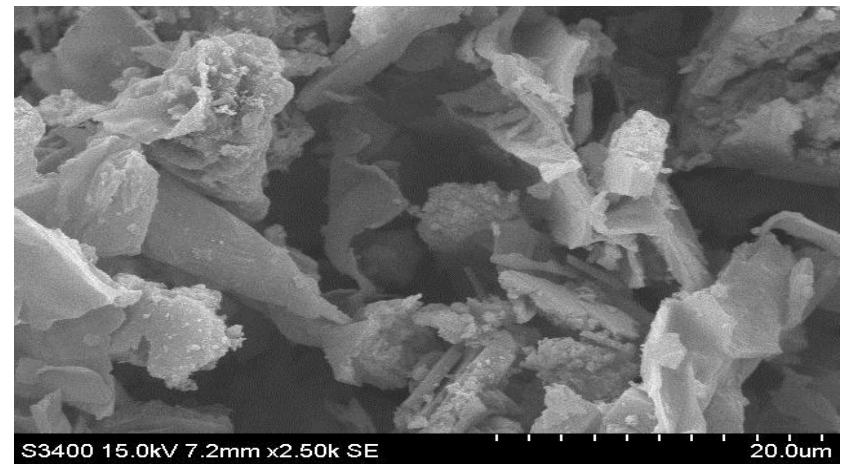

Fig 4. SEM photograph at 3400x magnification and $20 \mu \mathrm{m}$ pore size

\section{X-Ray Diffraction}

XRD method is used to analyze the structure of materials and is performed by directing an X-ray beam at a sample. It is mainly used for phase identification of a crystalline material and can provide information on unit cell dimensions. From the Fig 5, reveals the crystalline carbonaceous structure of activated carbon. The sharp peak suggests better layer alignment which is the characteristic of a crystalline structure. The absence of sharp peaks in activated carbon suggests that it is predominantly amorphous structure which is advantageous property for well-defined adsorbents.

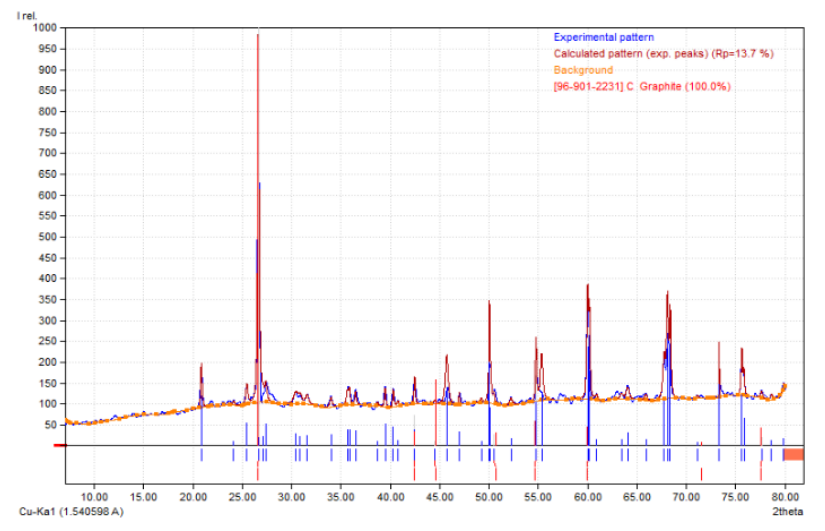

Fig 5. XRD Analysis Graph

According to JCPDS (Joint Committee on Powder Diffraction Standards), the sample peaks were matched with the standard peaks and the scattering intensity of carbon was identified.

Table -1 Experiment Result

\begin{tabular}{|ll|l|l|}
\hline Entry number & Amount & $\begin{array}{l}\text { Chemical } \\
\text { Formula }\end{array}$ \\
\hline $96-901-2231$ & 100 & $100 \%$ & C \\
\hline
\end{tabular}

\section{CONCLUSION}

The activated carbon was successfully prepared from agriculture waste (green coconut shells. From FTIR the presence of elements like carbon, hydrogen, oxygen and nitrogen and their bonds was observed. XRD gives sharp peaks which show the crystalline structure of activated carbon. The use of $\mathrm{H}_{2} \mathrm{SO}_{4}$ for activation increases the pore size distribution of activated carbon and the adsorption potential as it is significantly affected by activation method. The manufactured activated carbon can be effectively used in removal of dyes from textile industrial waste.

\section{REFERENCES}

[1] O.S.Amuda, A.A.Giwa, I.A.Bello, 2007, "Removal of heavy metal from industrial waste water using modified activated coconut shell carbon", Biochemical Engineering Journal, 174-181.

[2] Dipa Das, Debi Prasad Samal, Meikap BC, 2015, "Preparation of Activated Carbon from Green Coconut Shell and its Characterization", Journal of Chemical Engineering \& Process Technology, 278-291.

[3] Aseel M. Aljeboree, Abbas N.Alshirifi, Ayad F.Alkaim, 2014, "Kinetics and equilibrium study for the adsorption of textile dyes on coconut shell activated carbon", Arabian Journal of Chemistry, S3381-S3393.

[4] Jorge Laine, Simon Yunes, 1992, "Effect of the preparation method on the pore size distribution of activated carbon from coconut shell", Carbon, 4-12.

[5] Olafadehan O.A. Jinadu O.W., SalamiL., Popoola O.T., 2012, "Treatment of brewery wastewater effluent using activated carbon prepared from coconut shell", International Journal of Applied Science and Technology, 871-888.

[6] G.J.McDougall, 1991, "The physical nature and manufacture of activated carbon", J. S. Afr. Inst. Min. Metal, 76-89.

[7] C. John Kirubakaran, K. Krishnaiah, S. K. Seshadri, 1991, "Experimental Study of the Production of Activated Carbon from Coconut Shells in a Fluidized Bed Reactor", Ind. Eng. Chem. Res., 2411-2416.

[8] Jorge Laine, Santiago Simoni, Ricardo Calles, 1991, "Preparation of activated carbon from coconut shells in small scale cocurrent flow rotary kiln", Chem. Eng. Comrn., 15-23.

[9] Hata M1, Amano Y, Thiravetyan P, Machida M., "Preparation of Bamboo Chars and Bamboo Activated Carbons to Remove Color and COD from Ink Wastewater", Water Environment Research, 950-957.

[10] Y.Wang, X.J.Wang, M.Liu, X.Wang, Z. Wu, L.Z.Yang, S.Q.Xia, J.F.Zhao, 2012, "Cr(VI) removal from water using cobalt-coated bamboo charcoal prepared with microwave heating", Industrial Crops and Products, 81-88.

[11] Masatsugu Fujishige, Ichiro Yoshida, Yumiko Toya, Yasuo Banba, Kyo-ichi Oshida, Yu-suke Tanaka, Paweena Dulyaseree, Winadda Wongwiriyapn, Kenji Takeuchia, 2017, "Preparation of activated carbon from Bamboo-cellulose fiber and its use for EDLC electrode 
material", Journal of Environmental Chemical Engineering, 356-365.

[12] J.Zhang, Zhaoping Zhong, Houkun Guo, Xiaoxiang Jiang, 2012, "Preparation of Bamboo-Based Activated Carbon", Thermoenergy Engineering Research Institute Southeast University Nanjing, 456-462.

[13] S. MA Mahanim, Wan Asma Ibrahim, Rafidah Jalil, Puad Elham, 2011, "Production of activated carbon from industrial bamboo waste", Journal of Tropical Forest Science, $417-424$.

[14] Diya'uddeen, Mohammed, Ahmed, Jibril, 2008, "Production of Activated Carbon from Corncobs and its Utilization in Crude Oil Spillage Clean Up", Agricultural engineering international: The CIGR Ejournal, 57-68.

[15] William Buah, Jennifer MacCarthy, Samuel Ndur, 2016, "Conversion of Corn Cobs Waste into Activated Carbons for Adsorption of Heavy Metals from Minerals Processing Wastewater", International Journal of Environmental Protection and Policy, 98-103.

[16] P. Aggarwal, D. Dollimore, "The production of activated carbon from corn cobs by chemical activation", Journal of Thermal Analysis, 1997, 525-531.

[17] Thwe Linn, Su Wai Phyo, Khin Thet Ni, 2018, "Effectiveness of corn husk activated carbon on the abatement of sodium chloride content in fish sauce", Universal Journal of Agricultural Research, 91-97.

[18] Eric Paul Leimkuehler, Dr. Galen J. Suppes, 2002, "Production, characterization and applications of activated carbon", A Thesis presented to the Faculty of the Graduate School University of Missouri, 76-85.
[19] S Shahkarami, R Azargohar, AK Dalai, J Soltan, 2015, "Breakthrough CO2 adsorption in bio based activated carbons", J Env Sci, 68-76.

[20] E Taer, M Deraman, IA Talib, AA Umar, M Oyama, RM Yunus, 2010, "Physical, electrochemical and supercapacitive properties of activated carbon pellets from precarbonized rubber wood sawdust by $\mathrm{CO} 2$ activation", Cur Appl Phy, 1071-1075.

[21] C Srinivasakannan , MZ Abu Bakar, 2004, "Production of activated carbon from rubber wood sawdust", Biomass and Bioene, 89-96.

[22]. Krishnan, K.A., 2008, "Adsorption of nitrilotriacetic acid onto activated carbon prepared by steam pyrolysis of sawdust: Kinetic and isotherm studies", Colloids and Surfaces A: Physicochemical and Engineering Aspects, 344-351.

[23]. Malik, P.K., 2004, "Dye removal from wastewater using activated carbon developed from sawdust: adsorption equilibrium and kinetics",Journel of Hazardous Materials B113, 81-88.

[24]. Ruthven, D.M., 1998, "Principles of Adsorption and Adsorption Processes", Carbon 36, 13-87.

[25]. Mohanty, K., Das, D., Biswas, M.N., 2005, "Adsorption of phenol from aqueous solutions using activated carbons prepared from Tectona grandis sawdust by $\mathrm{ZnCl} 2$ activation", Chemical Engineering Journal, 121-131.

[26]. Hameed, B.H., Ahmad, A.L., Latiff, K.N.A., 2007, "Adsorption of basic dye (methylene blue) onto activated carbon prepared from rattan sawdust", Dyes and Pigments, 143-149. 